\title{
Thermal Behavior of 8-methacryloxy-quinoline-Acrylonitrile Copolymers
}

\author{
Mostafa Ali Mosalam (Corresponding author) \\ Faculty of Science, Banha University \\ PO box 11331, Cairo, Egypt \\ 5 Abdel Gelil Morsy, Kadek El Koba
}

Tel: 20-106-082-481Ｅ-mail: mostafaali19@yahoo.com

Sabrnal. H. El Hamouly

Faculty of Science, Mounofia University

Alsorok, Cairo, Egypt

Tel: 20-123-574-133 E-mail: prof_sabrnal2000@yahoo.com

Amaal Ahemad Mahmoud

Faculty of Science, Banha University

Banha, Egypt

Tel: 20-118-792-932Ｅ-mail: spanalchemical@yahoo.com

Ahemad Abd El Salam Khalil

Faculty of Science, BanhaUniversity

October Street, Cairo, Egypt

Tel: 20-182-236-311 E-mail: prof_ahemed555@yahoo.com

Received: October 11,2010 Accepted: October 29, 2010 doi:10.5539/ijc.v3n2p14

\begin{abstract}
Acrylonitrile was copolymerized with 8-methacryloxy-quinoline in Dimethylformamide using azobisisobutyronitrile as initiator. The composition of the copolymers was determined by nitrogen analysis and the monomer reactivity ratios $\left(r_{1}\right.$ and $\left.r_{2}\right)$ were calculated. Both the homopolymer and the copolymers was characterized by a variety of spectral and thermal methods. Thermogravimetry and differential thermal analysis data showed that the comonomer (MAQ) initiates the nitrile oligomerization reaction in the copolymer upon heating. A mechanism for the initiation of (MAQ) units in the nitrile copolymers was also proposed.
\end{abstract}

Keywords: 8-methacryloxy-quinoline, Thermal properties, Oligomers, Crosslinking

\section{Introduction}

The thermal degradation of polyacrylonitrile (PAN) and its copolymers in nitrogen as well as under nitrogen atmosphere was previously investigated by Coleman et al. Intramolecular cyclization, intermolecular crosslinking, and water elimination have been proposed. (El-Hamouly, 1994; Azab, 1994; Meneill, 1998; Jang, 2000; Anathalakshmi, 1999) Oxidative reactions were a major factor with subsequent heating. Grassie and McGuchan (1972) investigated the effect of copolymerization on the oligomerization of the nitrile group of PAN on heating.

The technological importance of PAN is known to suffer from several disadvantages: weak modability, color instability, and weak dyeability. Besides other efforts to abolish these difficulties, several monomers have been 
used as comonomers for the production of acrylonitrile (AN) copolymers (Grassie, 1971, 1974) with improved thermal stability.

The present study was conducted to investigate the effect of introducing a methacryloyloxy unit into the polymer chain of PAN. It was expected that the thermal properties of PAN would be greatly affected and, consequently, it was necessary to investigate the thermal behavior of the copolymers produced.

\section{Experimental}

\subsection{Materials}

Acrylonitrile (AN) was obtained from BDH (Toronto, Canada) and was purified by distillation before polymerization; 8-hydroxyquinoline was provided by (S.D.finechem.- Ltd., Mumbai, Indi) methacrylic acid (Aldrich) was distilled twice at reduced pressure; N,N-dicyclohexylcarbodiimide (DCCI) and azobisisobutyronitrile (AIBN) were from Merck (Darmstadt, Germany), Dimethylformamide (El gomheria, Cairo, Egypt) triethanolamine (S.D.finechem.- Ltd., Mumbai, Indi) and methacryloyl chloride (Aldrich).

\subsection{Synthesis of 8-methacryloloxy-quinoline (MAQ)}

MAQ was prepared by the reaction of 8-hydroxyquinoline with the corresponding acid chloride or by the reaction of 8-hydroxyquinoline with the corresponding acid as follows:

\subsubsection{Acid chloride method (Ferrnti, 1974)}

To a well-stirred solution of 8-hydroxyquinoline (14.5 g; $0.1 \mathrm{~mol})$ and triethylamine $(28.5 \mathrm{ml} ; 0.3 \mathrm{~mol})$ in $350 \mathrm{ml}$ of dry methylene chloride, $8.61 \mathrm{ml}(0.1 \mathrm{~mol})$ of methacryloyl chloride was added dropwise under cooling in ice bath $\left(0-5^{\circ} \mathrm{C}\right)$. After the complete addition of methacryloyl chloride, the reaction mixture was then allowed to stand at room temperature for $3 \mathrm{~h}$. the solvent was evaporated. The residue obtained was crystallized from diethyl ether (yield $80 \%$, m.p. $50^{\circ} \mathrm{C}$ ).

\subsubsection{N,N-Dicyclohexylcarbodiimide (DCCI) method (Ferrnti, 1975)}

To a well-stirred cooled solution $\left(0-5^{\circ} \mathrm{C}\right)$ of 8 -hydroxyquinoline $(2.9 \mathrm{~g} ; 1 \mathrm{~mol})$ and methacrylic acid $(3.44 \mathrm{ml} ; 2$ mol) in $300 \mathrm{ml}$ of dry methylene chloride, $4.12 \mathrm{~g}(0.1 \mathrm{~mol})$ of DCCI was added dropwise. The reaction mixture was stirred for $3 \mathrm{~h}$ at room temperature and the precipitated dicyclohexyl urea was removed by filtration. The resulting solution was evaporated under reduced pressure and the solid product was crystallized from diethyl ether (yield $70 \%$, m.p. $49-52^{\circ} \mathrm{C}$ ).

\section{$<$ Scheme 1 $>$}

\subsection{Polymerization procedures}

Ampoules of Pyrex glass were charged with the monomer mixtures, the solvent (DMF), and the initiator (AIBN). The ampoules were then cooled under nitrogen. The copolymerization was carried out in a water ultra -thermostat at $65^{\circ} \mathrm{C}$ with stirring for about $10 \mathrm{~h}$.

The contents were poured into a large excess of methanol. The polymers obtained were washed several times with hot methanol and dried at $50^{\circ} \mathrm{C}$ to constant weight. The nitrogen content of the copolymers was determined by a modified Kjeldahl method.

\subsection{Spectral measurements}

${ }^{1} \mathrm{H}-\mathrm{NHR}$ spectra were recorded on a Varian MR-400 spectrometer (Varian Associates, Palo Alto, CA) operating at $400 \mathrm{MHz}$ in deuterated $\mathrm{CDCl}_{3}$. IR spectra were recorded in $\mathrm{KBr}$ discs using a Shimadzu $470\left(4000-400 \mathrm{~cm}^{-1}\right)$ spectrophotometer (Shimadzu, Kyoto, Japan).The mass spectrum was measured on a Shimadu QP-Zolo plus Model spectrometer(Shimadzu, Kyoto, Japan) operating at 70eV.

\subsection{Thermal analysis}

DTA was performed at a heating rate of $15^{\circ} \mathrm{C} \min ^{-1}$ using a Shimadzu X-30 thermal analyzer. TG thermograms were obtained at a heating rate of $10^{\circ} \mathrm{C} \mathrm{min}^{-1}$, using a DT-30 thermal analyzer (Shimadzu).

\section{Results and Discussion}

8-methacryloxy-quinoline (MAQ) monomer was prepared according to Scheme 1. The prepared monomer was a white powder, soluble in most organic solvents. The ${ }^{1} \mathrm{H}-\mathrm{NMR}$ spectrum of MAQ monomer (Fig. 1) showed the following there are three multiplet peak appear near $\delta 8.86-8.94, \delta 8.08-8.21$ and $\delta 7.25-7.75$,corresponding to the protons of quinolyl ring at 3,5,6,7 site, 4-site and 2 site respectively. $\left(\mathrm{s}, \mathrm{CH}_{3}\right)$ of MAQ appear near $\delta 2.15$ and the peaks for $\mathrm{CH}_{2}=\mathrm{C}$ protons of MAQ appear near $\delta 6.54$ and $\delta$ 5.82-5.86 respectively corresponding to DMSO. 
Structures of the prepared monomer (MAQ), homopolymer (PMAQ), and copolymer with AN were investigated by IR spectroscopy. The IR spectra showed bands at 2918, 1740, 1630, and $1400 \mathrm{~cm}^{-1}$ attributable to $v$ (C-H) aliphatic, $v(\mathrm{C}=\mathrm{O}), v(\mathrm{C}=\mathrm{C})$, and $v(\mathrm{C}-\mathrm{O})$, respectively. The spectrum of the copolymer shows a new band at 2363 $\mathrm{cm}^{-1}$ attributable to $v(\mathrm{C} \equiv \mathrm{N})$.

The mass spectrum of MAQ monomer is shown in Figure 2. The fragmentation patterns are represented in Scheme 2, which illustrates the most abundant fragments of MAQ monomer.

The copolymerization data of MAQ with $\mathrm{AN}$ in DMF at $65^{\circ} \mathrm{C}$ are summarized in Table 1 The reactivity ratios for the comonomer were calculated using the Kelen-Tudös equation. (Kelen, 1975) Figure 3 shows a plot for this system. The intercept at $\xi=0.403$ is equal to $r_{1}$ (MAQ) and that at $\eta=0.63$ is equal to $r_{2} / \alpha$, (Tu“do“ s, 1976) where $\alpha$ is an arbitrary parameter.

\subsection{Thermal behavior}

The thermal behavior of any polymer should be affected appreciably by the introduction of a comonomer in the polymer chain. It is thus important to investigate the thermal behavior of the prepared copolymers.

For this purpose four MAQ-AN copolymers containing 10, 20, 30, 40,50,60 and 70\% MAQ were prepared. The thermal characteristics of PAN were previously studied in detail by Grassie. (Grassie, 1977) In the present investigation, the thermal analysis of PAN is given as a reference; that is, the comparison of DTA and TG data of PAN and those of the corresponding PMAQ and copolymers will illustrate the effect of these comonomers on the thermal behavior of the products.

The DTA curves of PAN and PMAQ and those of the corresponding copolymers with AN are represented in Figure 4 The thermal analysis of PAN in air shows the usual thermogram with an initial decomposition at $320^{\circ} \mathrm{C}$ and a broad exotherm peak with a maximum at $340^{\circ} \mathrm{C}$, which results from the oligomerization of the nitrile groups and formation of some aromatic structures. (Grassie, 1977) However, the DTA curve of PMAQ shows exotherms with maxima at 180,273 and $459^{\circ} \mathrm{C}$, respectively, which may represent the hemolytic scission and complete decomposition.

Proposed homolytic scission of PMAQ was suggested from the fragmentation patterns obtained from the mass spectrum of MAQ monomer (Fig. 2). As illustrated in Scheme 2, the most abundant fragmentation is cleavage of the C-N bond, giving a parention of $m / z=69$ (methacryloyloxy unit). A similar result was obtained previously from the fragmentation patterns of $p$-acryloyloxy-tri- $n$-butyltin benzoate. (Azab, 1994; 2003) and fragmentation patterns of pentachlorophenyl Methacrylate (Azab, 2003) The exotherm at $459^{\circ} \mathrm{C}$ may represent a complete decomposition. Moreover, in a separate experiment when PMAQ was heated at $459^{\circ} \mathrm{C}$, a black soluble mass remained, indicating that no crosslinking reaction occurred.

The IR spectra of unheated MAQ and PMAQ samples at different temperatures are shown in Figure 5 The spectra show no change in most of the functional groups present upon heating to $250^{\circ} \mathrm{C}$. Above this temperature, the characteristic bands at 1400, 1740, and $3000 \mathrm{~cm}^{-1}$ attributed to $\left.v(\mathrm{C}=\mathrm{O}), v \mathrm{C}-\mathrm{O}\right)$, and $v(\mathrm{C}-\mathrm{H})$ aliphatic gradually decrease until they disappear at $600^{\circ} \mathrm{C}$. The above arguments indicated that the PMAQ homopolymer decomposed by increasing the temperature. The exotherm at $600^{\circ} \mathrm{C}$ represents a complete decomposition and $100 \%$ weight loss.

The DTA curves of MAQ-AN copolymers in Nitrogen (Fig. 4) show exotherms at 468, 500, 550,585 and $600^{\circ} \mathrm{C}$, reflecting many processes probably including scission, cyclization, crosslinking, and decomposition at the higher-temperature exotherm. The first stage of decomposition could be attributed to scission of the $\mathrm{C} \equiv \mathrm{N}$ bond in a manner similar to that occurring in the suggested degradation of homopolymers, followed by cyclization and crosslinking. The DTA peaks of the copolymers were shifted to lower temperatures relative to that of PAN, indicating an initiating effect of the MAQ comonomers by a cyclization process.

The IR spectra for the unheated and heated MAQ-AN copolymer 1 (40:60) (Fig. 5) show bands for unheated copolymer at 2240,1720 , and $1400 \mathrm{~cm}^{-1}$ that are attributed, respectively, to $v(\mathrm{C} \equiv \mathrm{N}), v(\mathrm{C}=\mathrm{O})$, and $v(\mathrm{COO})$. However, for heated MAQ-AN copolymer at $250,350,450$ and $600^{\circ} \mathrm{C}$ there is an appreciable decrease in the intensity of the $\mathrm{C} \equiv \mathrm{N}$ band at $2240 \mathrm{~cm}^{-1}$. The carbonyl band at $1720 \mathrm{~cm}^{-1}$ merges with the band at $1700 \mathrm{~cm}^{-1}$. The bands at 1700 and $1600 \mathrm{~cm}^{-1}$, characteristic for the $(\mathrm{C}=\mathrm{O})$ and $(\mathrm{C}=\mathrm{N})$ groups, are enlarged and broadened. (Grassie, 1972) These spectral changes reveal radical changes in the copolymer structure and must also be the result of a direct interaction between the nitrile group and the functional groups of the comonomer. In this interaction an initiation of cyclization and crosslinking reactions will occur.

The TG thermograms for PAN, MAQ, and the four different concentrations of MAQ-AN copolymers are given in Figure 6 The analysis shows the existence of two transitions, probably reflecting more than one process during 
the thermal degradation reaction. Also, the TG curves show an increase in the weight loss of the copolymer relative to that of PAN. This could be confirmed when the MAQ-AN copolymer was heated for about 5 min at $330^{\circ} \mathrm{C}$; a black insoluble mass remained, indicating an appreciable crosslinking reaction attributed to the cyclization process. Based on the above-mentioned thermal and spectral data, the mechanism in Scheme 3 is suggested for the thermal degradation of copolymers.

\section{Conclusions}

The thermal stability of the MAQ-AN copolymers showed that the MAQ comonomer initiates the nitrile oligomerization reaction in the copolymers upon heating and formation of some aromatic compounds.

\section{References}

Anathalakshmi, N. R., Wadgaonkar, P. P., Sivaram, S., Varma, I. K. (1999). Therm Anal Calorim, 58, 553.

Azab, M. M. (1994). J Appl Polym Sci, 51, 1937.

Azab, M. M. (1994). J Appl Polym Sci, 51, 1937.

Azab, M. M. (2003). J Appl Polym Sci, 91, 296, 302.

Coleman, M. M., Gordon, B. (1983). Anal Proc London, 20, 572.

Coleman, M. M., Sivy, G. T. (1983). Adv Chem Ser, 203, 559.

Coleman, M. M., Sivy, G. T., Painter, P. C., Synder, R. W., Gordon, B. Carbon. (1983). 21, 225.

El-Hamouly, S. H., Azab, M. M., El-Kafrowi, S. A. (1994). Thermochim Acta., 241, 57.

Ferrnti, P., Fere, A., Goltica, G. (1974). J Polym Sci, 12, 553.

Ferrnti, P.; Goltica, G. (1975). J Polym Sci, 13, 2859.

Grassie, N., Heaney, X. (1974). Eur Polym J, 10, 415.

Grassie, N., McGuchan, R. (1971). Eur Polym J, 7, 1357.

Grassie, N., McGuchan, R. (1972). Eur Polym J, 8, 243.

Grassie, N., McGuchan, R. (1972). Eur Polym J, 8, 862.

Grassie, N., McGuchan, R. (1973). Eur Polym J, 9, 507.

Grassie. N. (1977). Developments in Polymer Degradation, Applied Science: London; p. 137.

Jang, S. P., Kim, D. (2000). Polym Eng Sci, 40, 1635.

Kelen, T., Tu“do" s, F. (1975). J Macromol Sci Chem, 9, 1.

Meneill, I., Mahmoud, T. (1998). Polym Degrad Stab, 60, 449.

Tu"do" s, F., Kelen, T., Berezsnich, T., Turcsany, J. (1976). J Macromol Sci Chem., 10, 1513.

Table 1. Analytical Data for Copolymerization of MAQ with $\mathrm{AN}^{\mathrm{a}}$

\begin{tabular}{|c|c|c|}
\hline Feed composition (a) & Conversion (\%) & Copolymer composition (b) \\
\hline 0.1111 & 7.35 & 0.39 \\
\hline 0.25 & 8.67 & 0.41 \\
\hline 0.6667 & 9.01 & 0.724 \\
\hline 1.5 & 6.42 & 1.38 \\
\hline 2.33 & 5.2 & 1.63 \\
\hline
\end{tabular}

a (a) and (b) are the molar ratios of $M_{1} / M_{2}$ in the feed and copolymer, respectively, and $\mathrm{N}(\%)$ values were determined by a modified Kjeldahl method. 


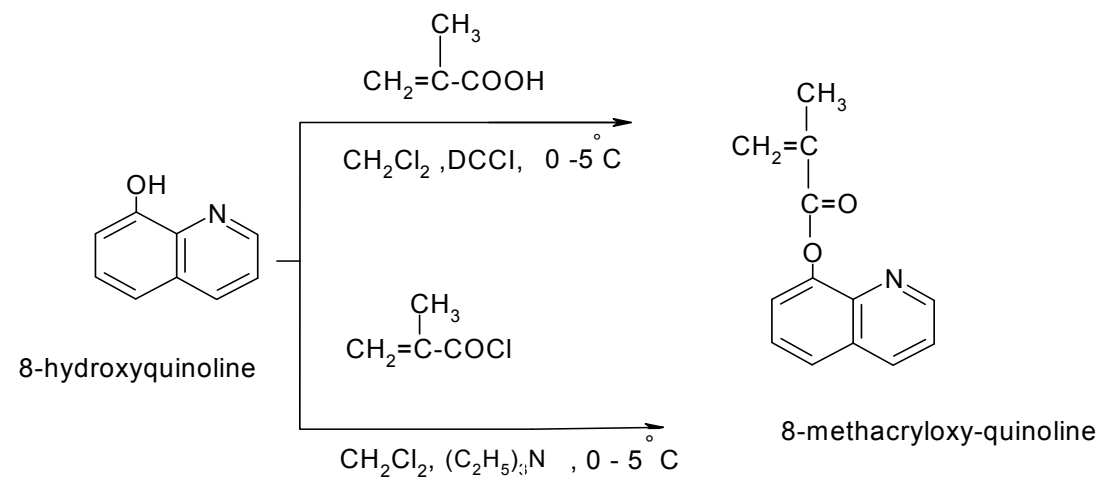

Scheme 1. Preparation of MAQ monomer

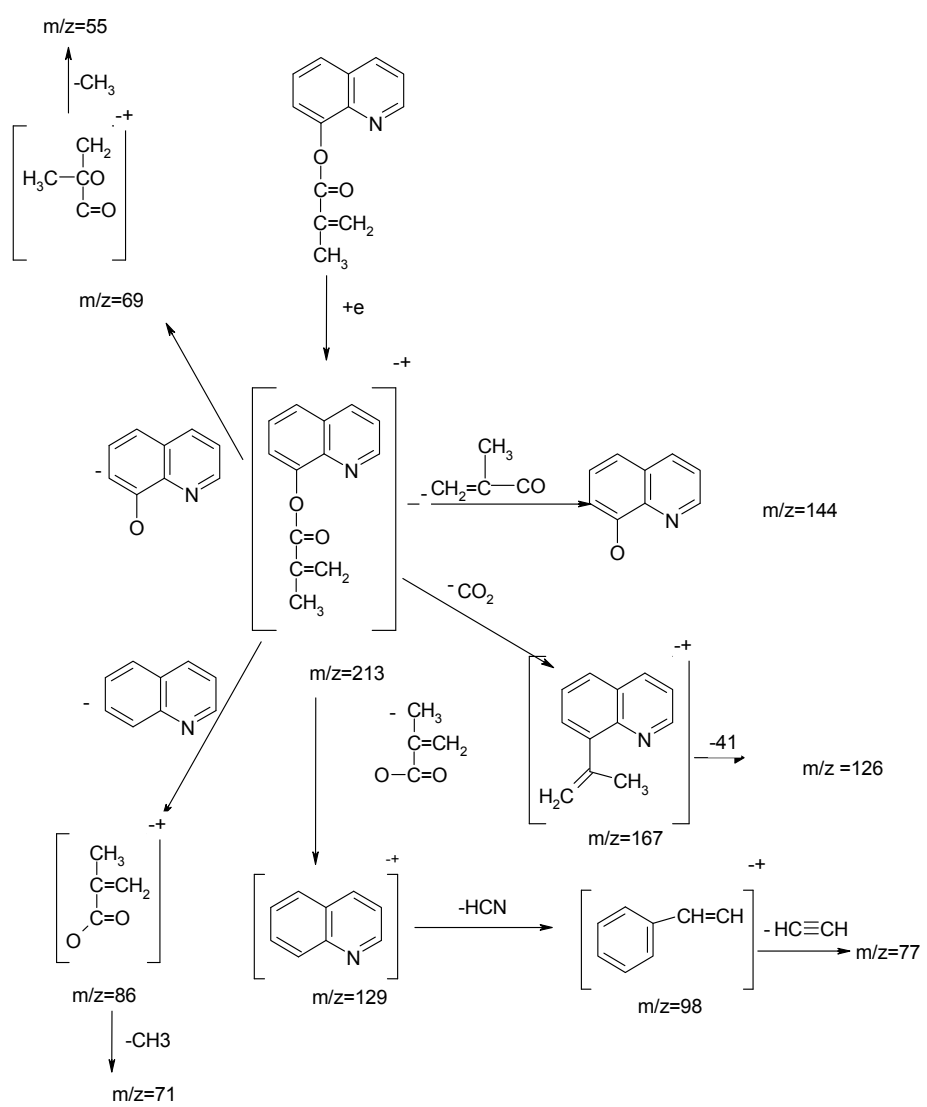

Scheme 2. Fragments of MAQ monomer 


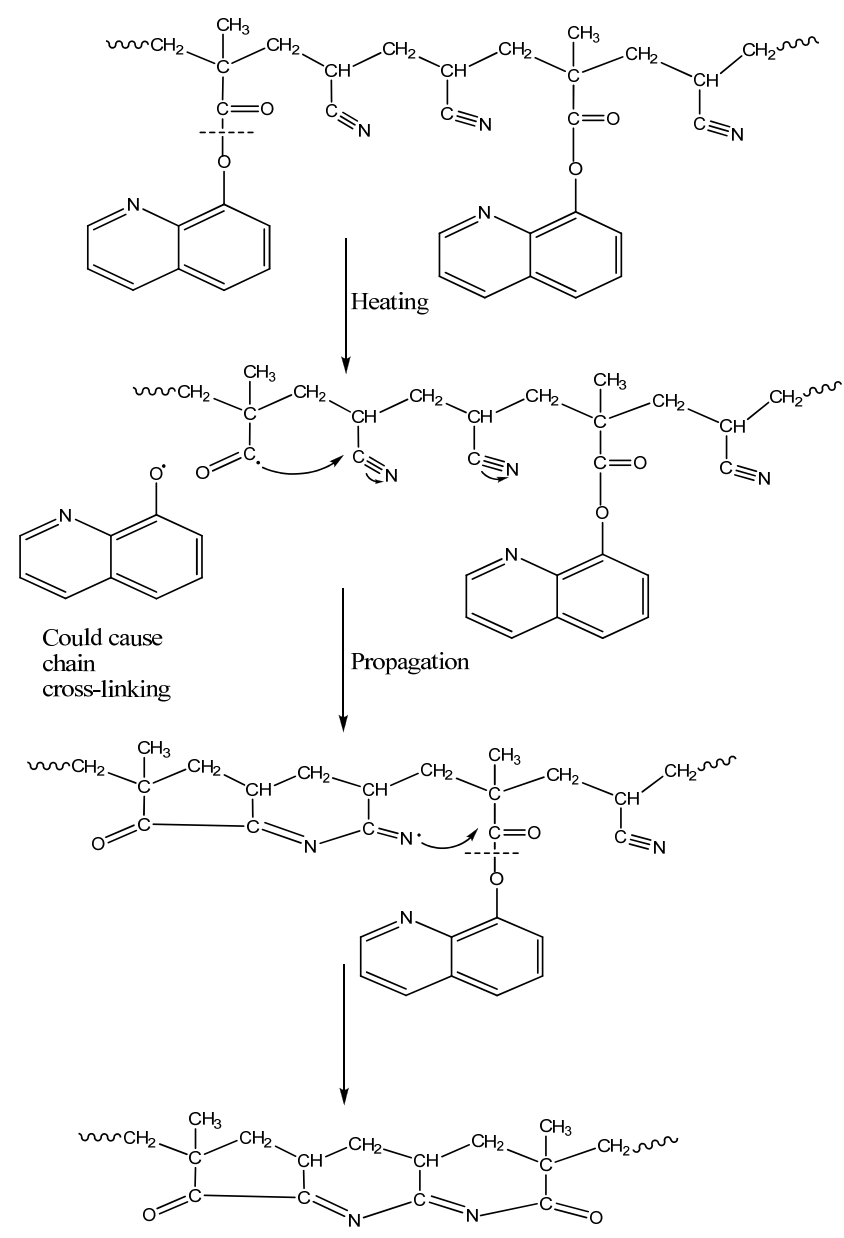

Scheme 3. Thermal degradation of MAQ-AN copolymer

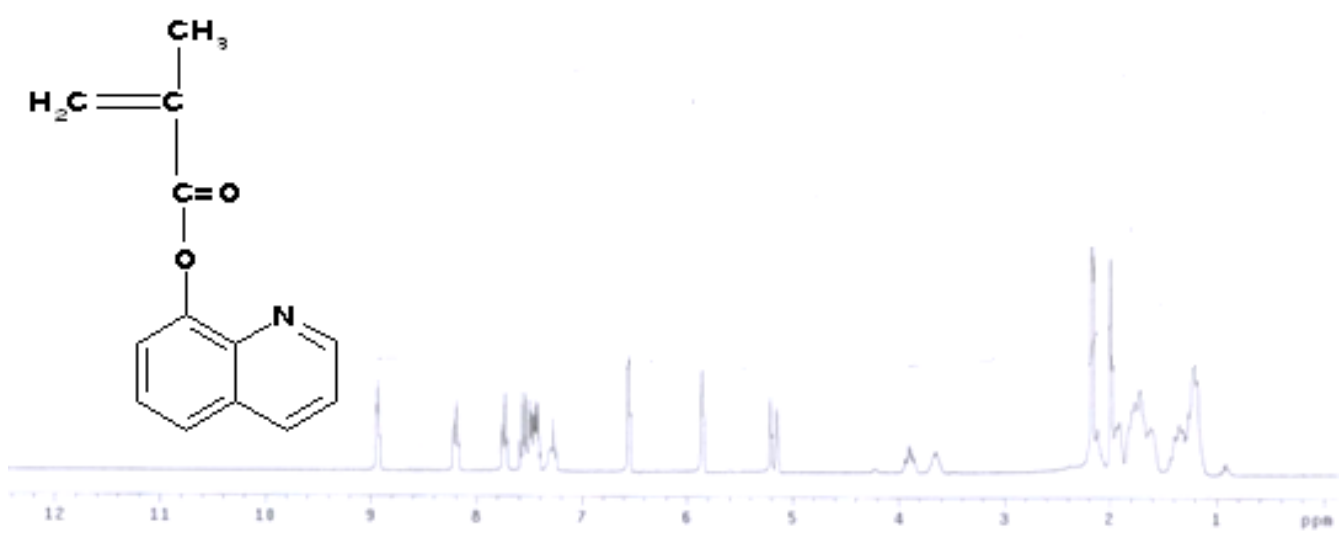

Figure 1. ${ }^{1} \mathrm{H}-\mathrm{NMR}$ spectrum of MAQ monomer 


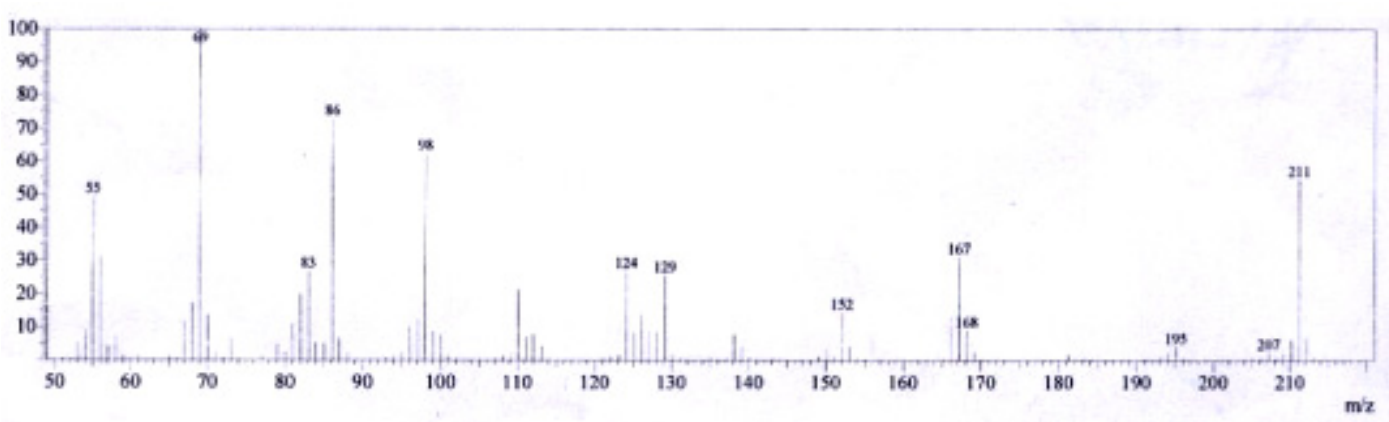

Figure 2. Mass spectrum of MAQ monomer

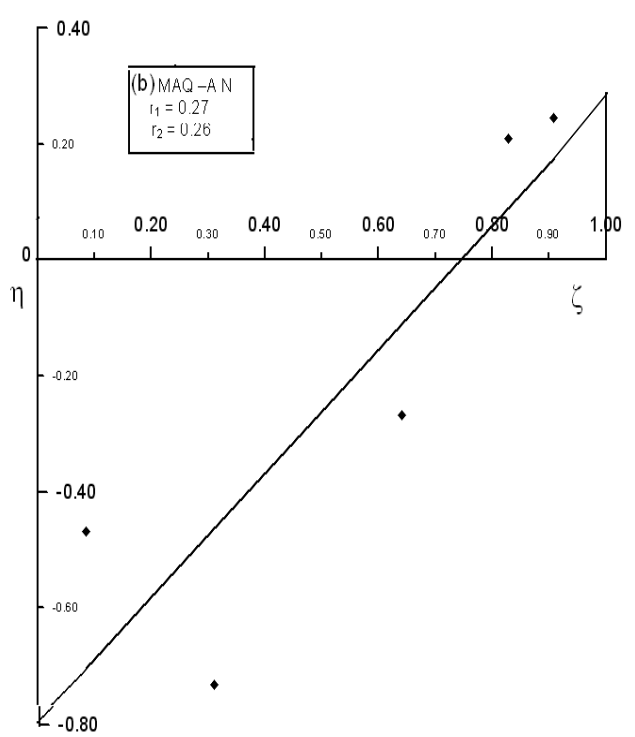

Figure 3. Kelen-Tu" do" s plot for copolymerization of MAQ monomer with AN $\xi=\left[a 2 /\left(a b \_a^{2}\right)\right]$ and $\eta=\{[a(b$ $\left.1)] /\left(b_{-} a^{2}\right)\right\}$, where $a$ and $b$ are the molar ratios $\left(M_{1} / M_{2}\right)$ of the comonomer in the feed and copolymer, respectively; and $=\left[\mathrm{a}_{\min } \mathrm{a}_{\max } / \mathrm{b}_{\min } \mathrm{b}_{\max }\right]^{1 / 2}$ 


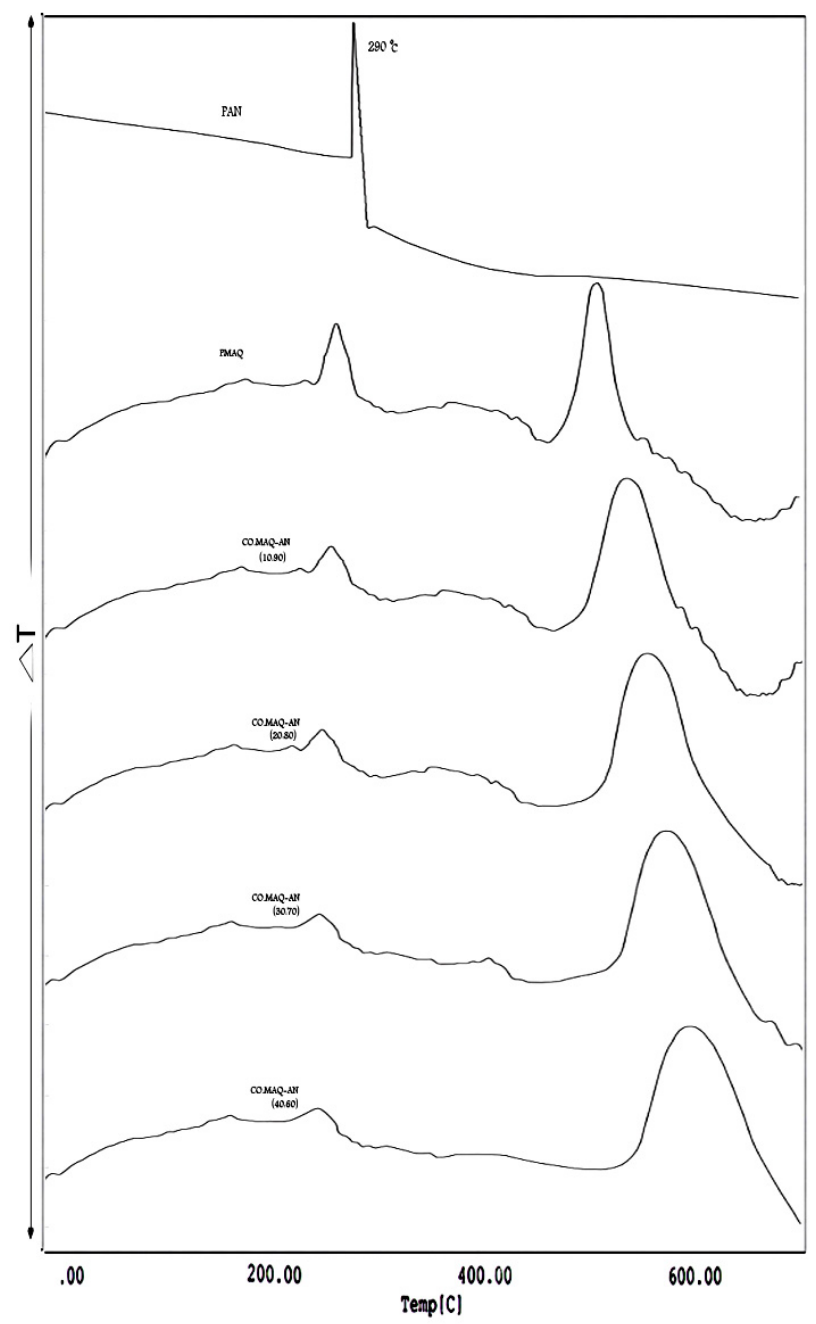

Figure 4. DTA curves for PAN, PMAQ, AN, and copolymer (MAQ-AN) in Nitrogen 


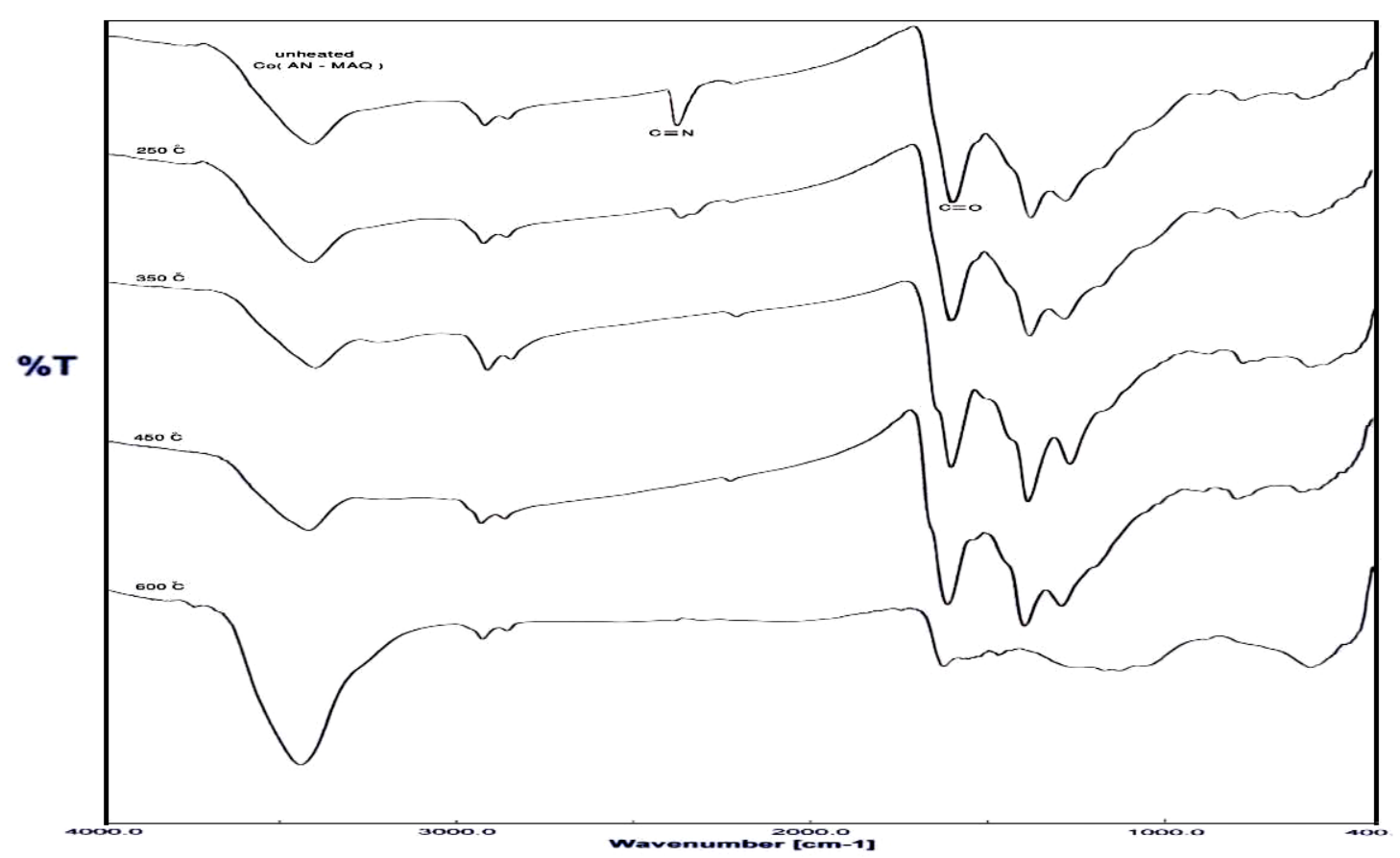

Figure 5. IR spectra of unheated and heated MAQ -AN copolymer

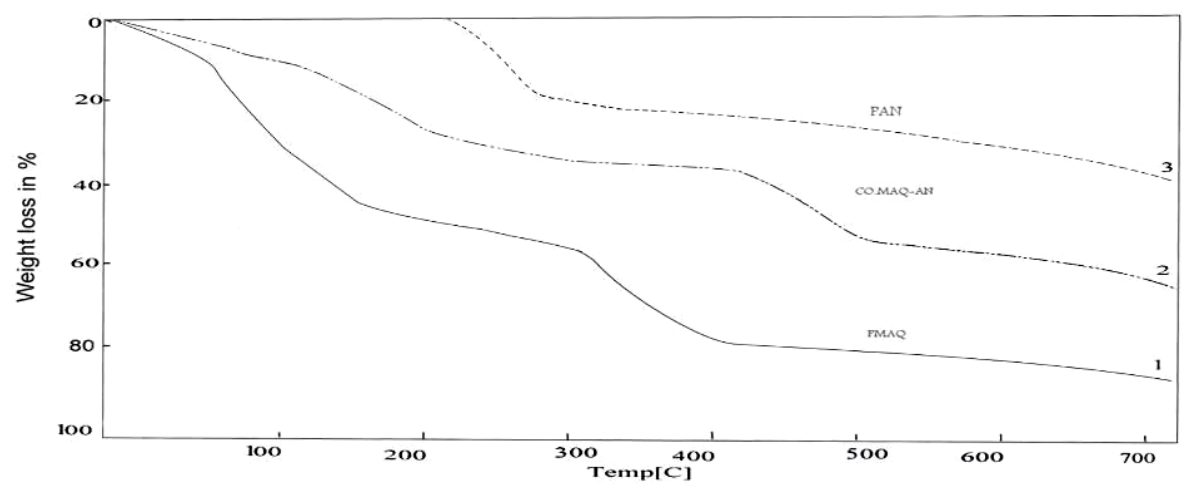

Figure 6. TG curves in $\mathrm{N}_{2}$ for PAN (------), MAQ -AN copolymer (--*) and P MAQ 